И.Б.Шуванова， В.П.Шувановой, С.А.Барановой, Ю.Э.Макаревской. 2016 Издательство Сочинский государственный университет, Сочи - С.216-218

4. Новикова С.С. Формирование профессионального мышления студентовпсихологов / Сборник материалов XIII Всероссийской научно-практической конференции. Под редакцией И.Б. Шуванова, С.В. Воронина, И.Г.Макаревской, Ю.Э. Макаревской, С.Н. Тесля, В.П. Шувановой. 2014 Издательство (Киров)

5. Новикова С.C. The levels of formedness of future of pedagogues/ psychologists' preparedness for professional orientation/ European Journal of Contemporary Education, №2 (8), 2014, C. 120-127

\title{
К ВОПРОСУ ОБ ИССЛЕДОВАНИИ ВОЗМОЖНОСТЕЙ МУЗЫКОТЕРАПИИ КАК СРЕДСТВА КОРРЕКЦИИ ЭМОЦИОНАЛЬНОГО ВЫГОРАНИЯ ПЕДАГОГОВ
}

Корнеева Е.Н., Ерофеева А.Г.

В настоящее время у лиц различных коммуникативных профессий, в частности, у педагогов, мы можем наблюдать ухудшение как физического, так и психического состояния здоровья. Высокие нагрузки, трудный контингент, с которым приходится работать, и множество иных факторов неизбежно ведет к хроническому стрессу, являясь предвестником эмоционального выгорания. Исходя из вышеизложенного, считаем данную проблему актуальной и требующей поиска новейших средств по предотвращению и коррекции данного феномена.

В исследованиях Н.В. Водопьяновой, К. Маслач и др. ранее было доказано, что представители образовательной сферы находятся в существенной группе риска относительно возникновения эмоционального выгорания [2; 6; 7].

Резюмируя все имеющиеся данные, нами была составлена программа исследования уровня эмоционального выгорания среди педагогов различных групп. В эти группы вошли представители начальной, средней школ, а также преподаватели ВУЗов г. Ярославля. В настоящее время обследовано 22 педагога, в дальнейшем планируется увеличение количества участников исследования.

Процентное соотношении участников нашего исследования можно увидеть на рисунке 1. 


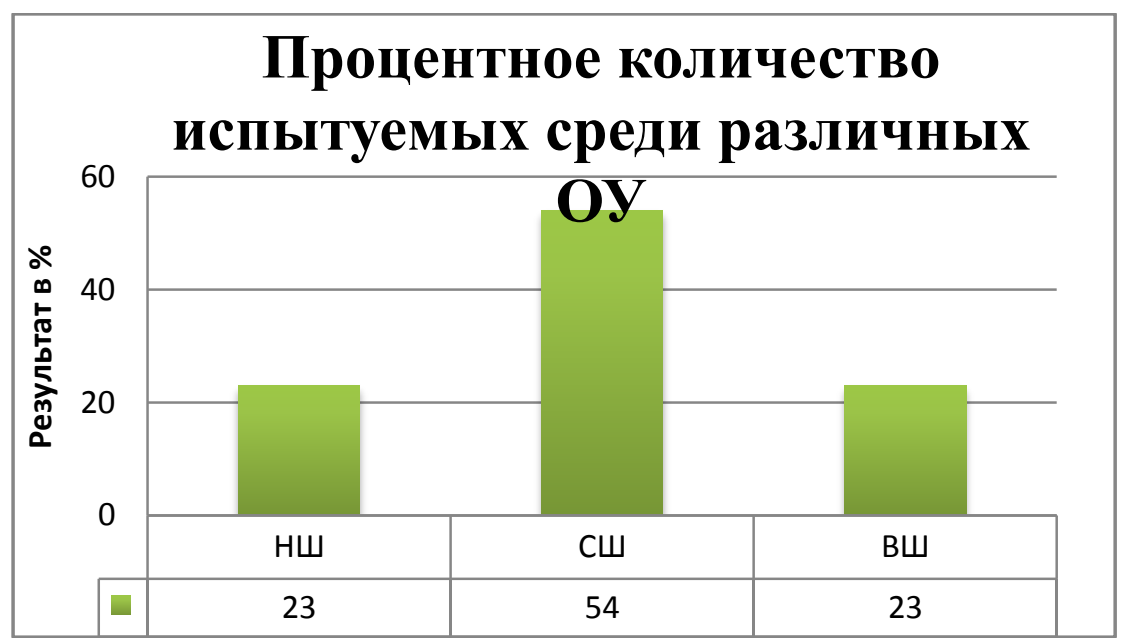

Рис.1 Процентное соотношение участников исследования

Как видно из рисунка 1, подавляющее большинство участников исследования - учителя средней школы образовательных организаций г. Ярославля (54\%), группу учителей начальных классов составляют 23\%, а преподаватели ВУЗов - также $23 \%$.

Как уже отмечалось ранее, эмоциональное выгорание характеризуется различными признаками. В своих исследованиях В.В. Бойко отмечал, что существенным признаком эмоционального выгорания является ухудшение общего самочувствия, появление психосоматических расстройств и заболеваний [1].

В связи с этим, нами были проанализированы также медицинские сведения об объективном состоянии здоровья испытуемых на сегодняшний день. Одним из таких показателей является группа здоровья, которая оценивает актуальное физиологическое состояние.

В медицинской литературе указано, что у взрослого населения выявляется основные 3 группы здоровья [4].

Так, к I группе здоровья относят здоровых, не имеющих видимых и латентных физиологических и психических патологий, людей.

Ко II группе здоровья относят людей, у которых возможен риск возникновения заболеваний или имеющих хроническое неинфекционное заболевание в стадии компенсации.

K III группе здоровья относят людей, имеющих хронические заболевания, которые вызывают периоды обострения и ремиссии. Такие люди чаще остальных нуждаются в своевременной диспансеризации и медицинской помощи [4].

Было установлено, что обследованные на текущий момент педагоги в большинстве случаев имеют III группу здоровья (соответственно 68\%). Часть с I группой здоровья составляет только 5\%, а II группа здоровья представлена $27 \%$ испытуемых. Таким образом, подавляющее большинство участников исследования имеют III группу здоровья, которая характеризуется наличием каких-либо хронических соматических заболеваний с сохраненными функциональными возможностями.

Для наглядности данные отражены в рисунке №2. 


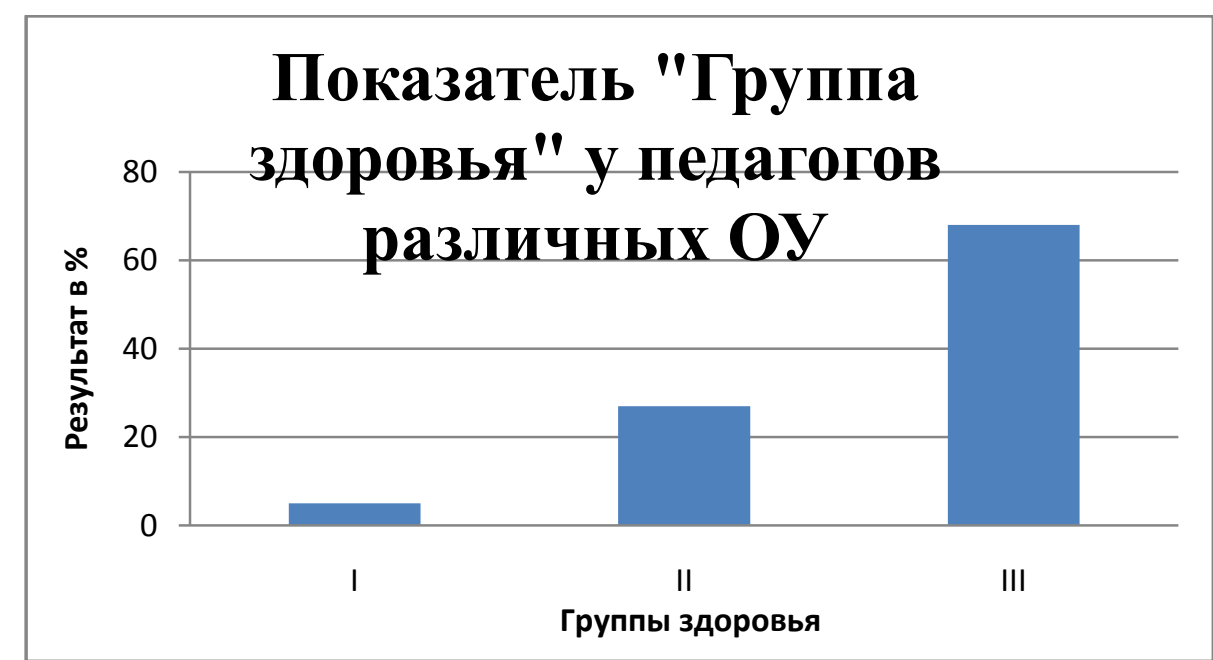

Рис.2 Процентные показатели «Группы здоровья» среди педагогов различных ОУ

Кроме вышеизложенных показателей, нами был рассмотрен также стаж педагогической деятельности участников исследования.

Стаж был разделен на 3 группы: от 0 до 5 лет, от 6 до 10, а также более 11 лет. Данные представлены в рисунке №3.

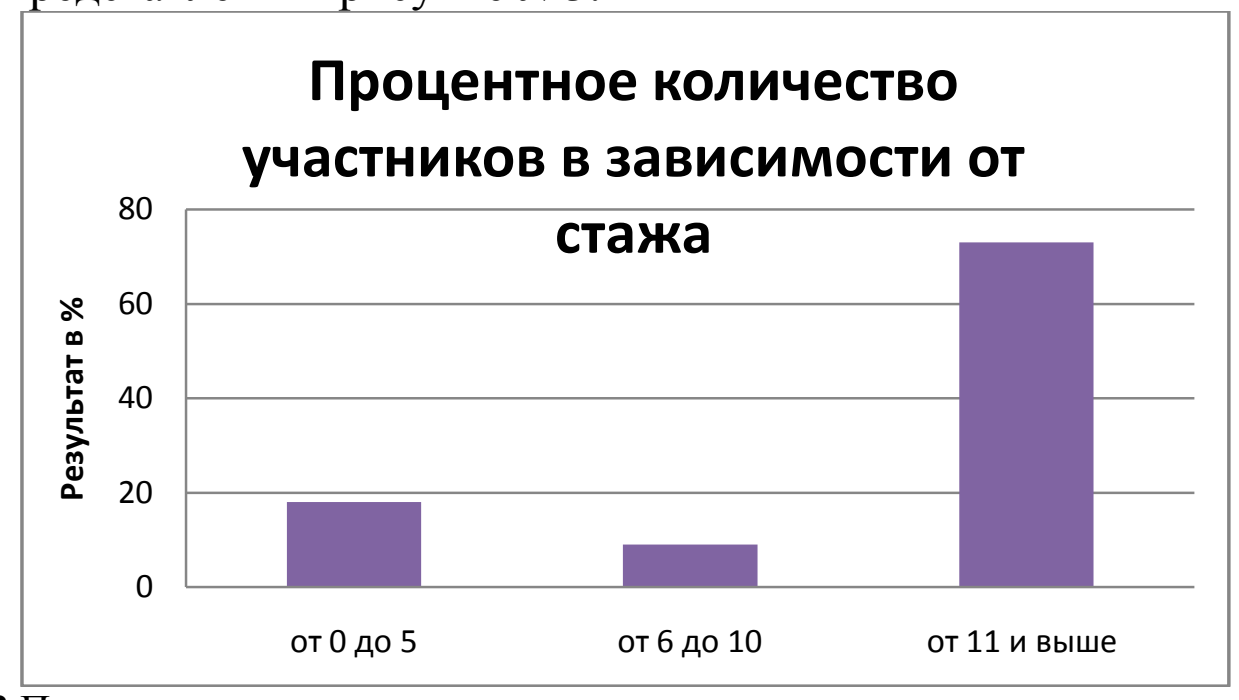

Рис.3 Процентное количество участников исследования в зависимости от стажа

Из рисунка №3 видно, что 73\% испытуемых имеют стаж более 11 лет, 9\% имеют стаж от 6 до 10 лет, а $18 \%$ - лица со стажем педагогической деятельности до 5 лет.

Таким образом, большинство участников исследования (73\%) имеют большой стаж педагогической деятельности.

Анализируя взаимосвязь между стажем работы и уровнем здоровья, можно предположить, что чем выше стаж, а также возраст работника, тем более низкий уровень здоровья мы можем наблюдать.

Далее нами было запланировано исследование актуального уровня эмоционального выгорания педагогов. В качестве методического инструментария нами были отобраны методики А.А. Рукавишникова, В.В. Бойко, а также MBI в адаптации Н.В. Водопьяновой [5].

После выявления актуального уровня эмоционального выгорания, нами планируется разработка программы психотерапевтического воздействия с 
использованием музыкальных возможностей. В частности, нами предполагается использование репертуара эстрадной музыки 70-90-хх гг. ХХ века. Сюда войдут лирические произведения Анны Герман, а также Татьяны Снежиной. При этом мы предполагаем, что на лиц, подверженных эмоциональному выгоранию, данный вид музыкотерапевтического воздействия будет оказывать положительное влияние [3].

Дальнейшая работа будет включать в себя исследование психического состояния педагогов непосредственно после прослушивания лирических произведений Анны Герман и Татьяны Снежиной. Для проверки указанной ранее гипотезы считаем целесообразным использование методики диагностики психических состояний Г. Айзенка, а также методики САН («Самочувствие, активность, настроение»). Известно, что критерии и шкалы, оцениваемые в данных методиках, являются существенными составляющими и сопутствующими эмоциональному выгоранию [3].

Таким образом, в результате проведенного исследования, нами планируется разработка рекомендаций по предотвращению и коррекции эмоционального выгорания для педагогических работников, в том числе с использованием музыкотерапевтических средств [3].

\section{Литература}

1. Бойко, В.В. Синдром «эмоционального профессиональном общении. СПб.: Сударыня, 1999. - 210 с.

2. Водопьянова, Н. Е., Старченкова, Е. С. Синдром выгорания: диагностика и профилактика. - СПб.: Питер, 2008. - 71 с.

3. Корнеева, Е.Н. Субъектная регуляция образовательного взаимодействия - Ярославль: изд-во ЯГПУ, 2007. - 153 с.

4. Об утверждении порядка проведения диспансеризации определенных групп взрослого населения [Электронный ресурс]: Приказ Министерства здравоохранения РФ от №36ан// http://ivo.garant.ru//document/70883132/paragraph/1:4. Дата обращения: 02.04.2017.

5. Райгородский, Д.Я. Практическая психодиагностика. Методики и тесты. Учебное пособие. - Самара: изд-во «БАХРАХ-М», 2015. - 672 с.

6. Barth A.-R. Burnoutbei Lehrern.-Hogrefe-Verlag, 1997. - 268 s.

7. Maslach, C. Job Burnout Text. / C. Maslach, W. B. Schaufeli, M. P. Leiter//Annual Review of Psychology, 2001.- Vol.52. - P.397-422.

\section{ОСОБЕННОСТИ СТИЛЯ ПЕДАГОГИЧЕСКОЙ ДЕЯТЕЛЬНОСТИ В СИСТЕМЕ ШКОЛЬНОГО ДОПОЛНИТЕЛЬНОГО ОБРАЗОВАНИЯ Кочконян К.В. Научный руководитель: д.п.н., профессор Шаповалов В.И.}

Индивидуальность человека, неповторимость, уникальность, активность, творческий подход к профессии, востребован в современной и стремительно меняющейся жизни. Воспитать такую личность способен лишь педагог 